Chapter 10

\title{
Laboratory Investigations of Hydraulic Fractures in Naturally Fractured Formations
}

\author{
Guangqing Zhang and Tiegang Fan \\ Additional information is available at the end of the chapter
}

http://dx.doi.org/10.5772/64559

\begin{abstract}
Researchers have recently realized that hydraulic fracture networks are significant for the exploitation of unconventional reservoirs (tight gas, shale gas, coalbed methane, etc.). Laboratory experiments are proposed to study the evolution of fracture networks in natural fractures. The density of natural fractures and injection rate were selected as the primary dominating factors. It was concluded that the interaction between reopening and connecting of natural fractures led to hydraulic fracture networks, which can be detected by pressure fluctuations. The fracture network is composed of multiple fractures, resembling an ellipsoid with the major axis different from the maximum horizontal stress direction. The treatment pressure will be substantially raised by both the great natural fracture density and high injection rates.
\end{abstract}

Keywords: hydraulic fractures, naturally fractured formation, fracture initiation, interferences

\section{Introduction}

Natural fractures have substantial effects on hydraulic fracture propagation, since hydraulic fractures will interact with the natural fractures during propagation, leading to complex growth patterns of fracture systems.

Researchers employed both experimental [1-5] and numerical [6-12] means to investigate the interaction between hydraulic and natural fractures. It is found that the controlling factors include horizontal stress difference, the angle of approaching, and treatment pressure [2-4]. The interaction between hydraulic fracture and natural fractures can be categorized into four types. Hydraulic fracture can cross natural fractures, as if natural fractures do not exist. The 
hydraulic fracture may be completely hindered or arrested at the natural fractures, either by opening natural fractures or causing both faces slipping. Or, hydraulic fractures may start new fractures to form fracture branches. And hydraulic fracture might follow natural fractures for a short distance and initiate a new fracture on natural fractures along the maximum stress direction [1, 2, 13-15]. Multiple hydraulic fractures were also observed in field experiments [16-19], inducing abnormally high treating pressure and implying reduced fracture width. The reduced width of each fracture is caused by competition among multiple fractures [9].

The effect of natural fractures on hydraulic fracture was realized and investigated very early $[3,20,21]$, with the emphasis on a single natural fracture. De Pater and Beugelsdijk [22] investigated the effect of the injection rate on fracture propagation, with Portland cement model blocks containing heating-induced prefractures. The tests showed that a high flow rate or viscosity was necessary for generating new fractures. Zhou and Xue [23] conducted similar tests, and they found three types of fracture geometries: a vertical main fracture with various branches; radial fractures around a wellbore; and one wing vertical fracture with branches. However, heating-induced fractures are not easy to control to simulate natural fractures, thus causing much uncertainty in pinpointing the factors for hydraulic fractures. Olson et al. [24] used cast hydrostone blocks embedded with planar glass sheet to study the effects of cemented natural fractures on hydraulic fracture propagation. They found that oblique natural fractures will divert a hydraulic fracture more easily than the orthogonal natural fractures.

Laboratory experiments are considered as the direct way to investigate fracture propagation, because numerical simulation needs to be further improved in terms of constitutive modeling, boundary conditions. Meanwhile, it is very costly and hard to retrieve cores for research purposes, and the size of cores is usually too small to meet the needs of laboratory tests for hydraulic fracturing. Therefore, researchers tend to select outcrops and artificial specimens for laboratory tests of hydraulic fracturing. And homogeneous and continuous blocks are often used, in which no natural fractures are included. However, natural fractures are present frequently in formations, and in laboratory tests it seems necessary to consider the effects of natural fractures on hydraulic fracturing. Many researchers [4, 22-24] proposed different methods to take natural fractures into consideration.

Natural fractures seldom are found alone, however, several groups of natural fractures exist in reservoir formations. La Pointe and Hudson [25] presented methods for describing parameters of natural fractures, such as spacing, density, and trace length. As per Lachenbruch [26], there are two types of fracture intersection: orthogonal and nonorthogonal, which can be divided into three sets: all continuous; part continuous and part discontinuous; and all discontinuous. In this study, laboratory experiments were conducted with natural and artificial specimens, which contain natural fractures or prefractures to investigate the influence of natural fracture on the hydraulic fracture propagation behaviors.

In this chapter, laboratory work is conducted on specimens of coal, shale, and artificial hydrostone, for simulating hydraulic fracturing in naturally fractured reservoirs. The equipment used in the laboratory work is capable of applying independent stresses along three directions, while injecting pressurized fluid into the specimens. Hydraulic fractures induced 
during the experiments can be observed directly either by slicing the specimens or just splitting along the fractures.

\section{Experimental setup and procedures}

\subsection{Experimental equipment}

The hydraulic fracturing experiments reported here were conducted using a true tri-axial hydraulic fracturing test system (Figure 1).

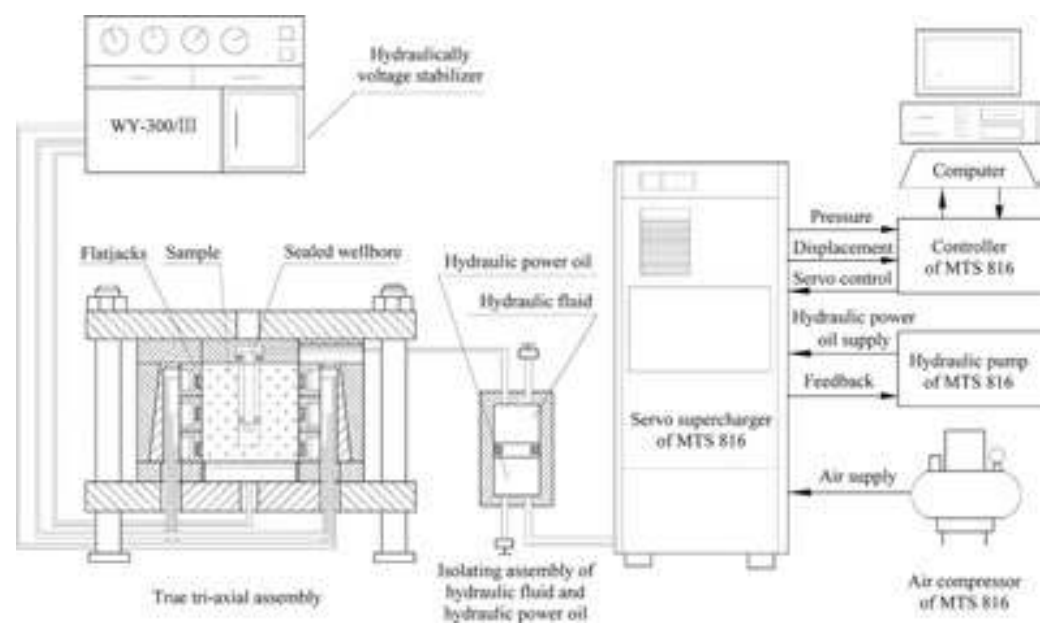

Figure 1. Schematic of the true tri-axial hydraulic fracturing test system.

All of the external stresses are applied using a set of hydraulic stabilizer, and the injection pressure is provided by a servo-controlled hydraulic pump of MTS 816. Up to $28 \mathrm{MPa}$ of external stresses and injection pressures of up to $140 \mathrm{MPa}$ can be supplied to cubic samples whose side is 300 or $400 \mathrm{~mm}$ long. Various injection scheme of pumping fracturing fluids can be supported. The experimental implementation and data collection are conducted using software on a PC computer. Various testing materials and fracturing fluids were used to initiate and propagate hydraulic fractures.

\subsection{Experimental arrangements}

\subsubsection{Hydraulic fracturing experiment of coal}

Fractures occur in nearly all coal seams. Coal fractures have been investigated since the early days of coal mining, and published descriptions and speculation on the origin of fractures date 
from early in the nineteenth century [27]. Over the years, many different terms were used for natural fractures in coal, people prefer to the ancient mining term: cleats [28].

In coal-seam, water and gas flow in the cleat system, which is composed of two or more sets of parallel or subparallel fractures. However, natural fractures are irregular discontinuities.

The coal specimens for the hydraulic fracturing were cut from the outcrop, Shenmu, China. Usually, the blocks from outcrops should be much larger in size than the required, for there are many weak discontinuities inside. Therefore, the coal blocks were cut and finished with a saw-cutter into cubes of $300 \mathrm{~mm}$ on each side.

After being cut, further treatments of polishing the surface are needed to fit the loading frame dimensions, and a borehole of $20 \mathrm{~mm}$ in diameter, $160 \mathrm{~mm}$ in depth is prepared, before a metal casing of $10 \mathrm{~mm}$ in diameter is inserted and cemented. An open borehole of $200 \mathrm{~mm}$ interval at the end of the block should be left for easy fracture initiation.

During testing, the true tri-axial equipment was used to load the cubic specimens by three independent flat jacks to simulate three orthogonal stresses. And thin Teflon sheets were also inserted between the specimen and the flat jacks, for reducing shearing stress [22]. A normalfaulting stress regime was adopted in our experiments, and the three orthogonal stresses were applied hydrostatically to the minimum stress level firstly, and the other two stresses were raised to the designed levels respectively (see Table 1). About 30 min were allowed to hold at the predefined stresses before the hydraulic fracturing tests begin [29].

\begin{tabular}{lllllll}
\hline $\begin{array}{l}\text { Test } \\
\beta^{\mathrm{a}}\end{array}$ & $\begin{array}{l}\text { Vertical } \\
\text { stress } \\
\sigma_{\mathrm{v}}, \mathbf{M P a}\end{array}$ & $\begin{array}{l}\text { Maximum } \\
\text { horizontal } \\
\text { stress } \\
\sigma_{\mathrm{H}}, \mathbf{M P a}\end{array}$ & $\begin{array}{l}\text { Minimum } \\
\text { horizontal } \\
\text { stress } \\
\sigma_{\mathrm{h},} \mathbf{M P a}\end{array}$ & $\begin{array}{l}\text { Injection } \\
\text { rate of } \\
\text { the fracturing } \\
\text { fluid } Q, \mathbf{m l} / \mathbf{m i n}\end{array}$ & $\begin{array}{l}\text { Fracturing } \\
\text { fluid }^{\mathrm{b}}\end{array}$ \\
\hline 1 & 5 & 18 & 7 & 5 & 20 & Guar-based gel \\
2 & 7 & 18 & 7 & 5 & 20 & Guar-based gel \\
3 & 10 & 18 & 7 & 5 & 20 & Guar-based gel \\
4 & 11 & 18 & 7 & 5 & 20 & Guar-based gel \\
5 & 20 & 18 & 7 & 5 & 20 & Guar-based gel \\
6 & 39 & 18 & 7 & 5 & 20 & Guar-based gel \\
\hline
\end{tabular}

$\mathrm{a} \beta$ is the angle between the face cleat and the maximum horizontal stress, degree.

bFracturing fluid is mixed with luminous yellow fluorescent dye.

Table 1. Parameters used in the experiment for the Shenmu coal.

\subsubsection{Hydraulic fracturing experiment of shale}

The shale specimens for the tests were cored from outcrops of Longmaxi formation of shale in Sichuan, China. The outcrops obtained in the field were irregular in shape and could not be 
used directly in the experiments. Therefore, in the experiments cubic specimens of $400 \mathrm{~mm}$ in lateral were used, and broken parts along the boundary were repaired with cements. A hole of $18 \mathrm{~mm}$ in diameter was made up to $210 \mathrm{~mm}$ deep, and then a metal casing was put and cemented in the hole, leaving about $20 \mathrm{~mm}$ open interval for fracture initiation. Figure 2 shows a picture of a specimen.

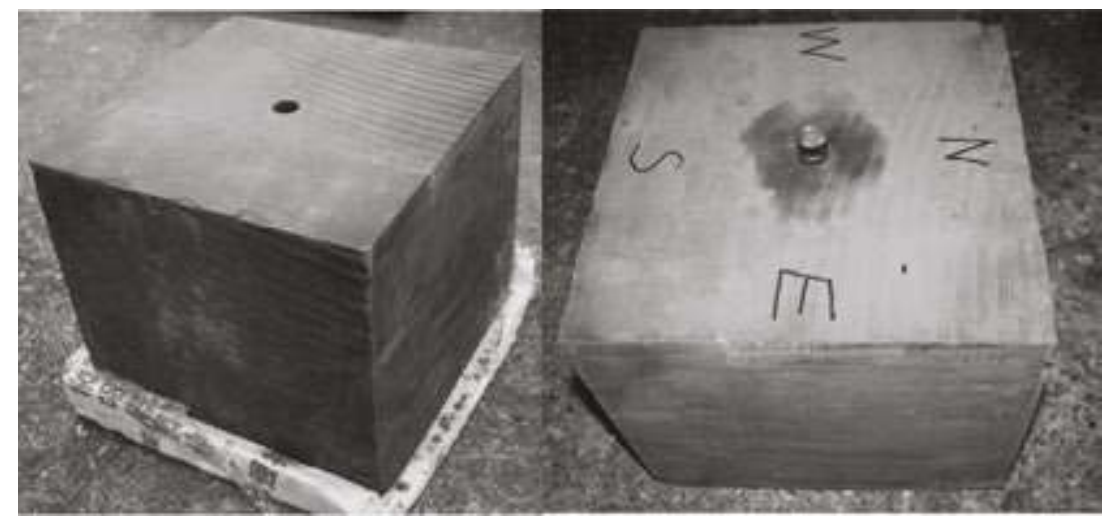

Figure 2. The shale specimen for hydraulic fracturing test.

For each experiment, fracturing fluid with luminous yellow fluorescent dye was injected at a constant flow rate (see Table 2). The fracturing fluid used was a guar-based gel mixed at $5 \mathrm{~g}$ gel powder/1000 $\mathrm{ml}$ water. This gel has an apparent viscosity of about $24.75 \mathrm{cP}$. The fluorescent dye is nonpenetrating and therefore shows the created fracture surface.

\begin{tabular}{|c|c|c|c|c|c|c|}
\hline Test & $\begin{array}{l}\beta^{\mathrm{a}} \\
\text { degree }\end{array}$ & $\begin{array}{l}\text { Vertical } \\
\text { stress } \\
\sigma_{\mathrm{v}}, \mathrm{MPa}\end{array}$ & $\begin{array}{l}\text { Maximum } \\
\text { horizontal } \\
\text { stress } \\
\sigma_{\mathrm{H}}, \mathrm{MPa} \\
\end{array}$ & $\begin{array}{l}\text { Minimum } \\
\text { horizontal } \\
\text { stress } \\
\sigma_{\mathrm{h}}, \mathrm{MPa} \\
\end{array}$ & $\begin{array}{l}\text { Injection } \\
\text { rate of the } \\
\text { fracturing fluid } \\
Q, \mathrm{ml} / \mathrm{min}\end{array}$ & $\begin{array}{l}\text { Fracturing } \\
\text { fluid }^{\mathrm{b}}\end{array}$ \\
\hline 1 & - & 15 & 12 & 10 & 10 & Guar-based gel \\
\hline 2 & - & 20 & 15 & 13 & 10 & Guar-based gel \\
\hline 3 & - & 20 & 15 & 13 & 20 & Guar-based gel \\
\hline
\end{tabular}

${ }^{a} \beta$ is the angle between the face cleat and the maximum horizontal stress, degree.

${ }^{b}$ Fracturing fluid is mixed with luminous yellow fluorescent dye.

Table 2. Parameters used in the experiment for the Sichuan shale.

In the experiments, the friction between the specimen and flat jacks can be great, leading to substantial shear force on the boundary. In order to minimize the shear forces [22], a thin Teflon sheet covered on both sides with Vaseline was inserted between the block and flat jacks. After 
each test, observation of friction scratch on the block surface was necessary for evaluation of shear force along the boundary. Before testing, the confining stresses along the three orthogonal directions were kept for about $30 \mathrm{~min}$, allowing stress equilibrium inside the specimen [29].

After a test, the specimen was opened with a hammer and chisel along the expected orientation. Under ultraviolet light, the luminous yellow fluorescent dye can clearly show the traces of hydraulic fracture.

\subsubsection{Hydraulic fracturing experiment of artificial specimens}

In this part, we used paper as the separating agent embedding the blocks for simulating a single natural fracture. There were types of paper: type one is rice paper of $0.06 \mathrm{~mm}$ thick, type two printing paper of $0.11 \mathrm{~mm}$ thick, and type 3 wrapping paper of $1.2 \mathrm{~mm}$ thick.

When the hydraulic fracture was approaching a natural fracture, the interaction between the hydraulic fracture and the natural fracture was determined by several factors, including the approaching angle, stress difference, and net pressure inside the hydraulic fracture. All the experiments were conducted with vertical wellbores. And horizontal stress difference along with stress regime was designed from the beginning of the tests. For each test conditions, three tests were performed to ensure the repeatability of the results.

In fracturing tests, red-dyed water was injected at a constant flow rate (see Table 3). The dye is nonpenetrating and therefore highlights the fracture surface generated by the experiment.

\begin{tabular}{|c|c|c|c|c|c|c|}
\hline Test & $\begin{array}{l}\text { Fracture } \\
\text { spacing } \\
(\mathrm{mm})^{\mathrm{a}}\end{array}$ & $\begin{array}{l}\text { Vertical } \\
\text { stress } \\
\sigma_{\mathrm{v}}, \mathrm{MPa}\end{array}$ & $\begin{array}{l}\text { Maximum } \\
\text { horizontal } \\
\text { stress } \\
\sigma_{\mathrm{H}}, \mathrm{MPa} \\
\end{array}$ & $\begin{array}{l}\text { Minimum } \\
\text { horizontal } \\
\text { stress } \\
\sigma_{\mathrm{h}}, \mathrm{MPa} \\
\end{array}$ & $\begin{array}{l}\text { Injection } \\
\text { rate of the } \\
\text { fracturing } \\
\text { fluid } Q, \mathrm{ml} / \mathrm{min}\end{array}$ & $\begin{array}{l}\text { Fracturing } \\
\text { fluid }\end{array}$ \\
\hline 1 & 30 & 15 & 8 & 5 & 6 & Red-dyed water \\
\hline 2 & 35 & 15 & 8 & 5 & 6 & Red-dyed water \\
\hline 3 & 40 & 15 & 8 & 5 & 9.6 & Red-dyed water \\
\hline 4 & 45 & 15 & 8 & 5 & 9.6 & Red-dyed water \\
\hline 5 & 50 & 15 & 8 & 5 & 9.6 & Red-dyed water \\
\hline 6 & 40 & 15 & 8 & 5 & 19.8 & Red-dyed water \\
\hline
\end{tabular}

${ }^{a}$ The distance between two adjacent cemented fractures in the specimens, $\mathrm{mm}$.

Table 3. Parameters used in the experiment for the artificial cement paste.

Six cubic specimens of $300 \mathrm{~mm}$ in lateral were used in the experiments, made out of a mixture of cement and 20-40 mesh siliceous sand. Small cuboid blocks of various sizes were prepared to assemble into a final specimen. And the scheme is shown in Table 4. 


\begin{tabular}{lllll}
\hline Test & Size $(\text { length } \times \text { width } \times \text { height })^{\mathbf{a}}$ & ${\text { Amount } / \text { set }^{\mathrm{b}}}^{\mathrm{b}}$ & Sets $^{\mathbf{c}}$ & Amount $^{\mathrm{d}}$ \\
\hline 1 & $30 \mathrm{~mm} \times 30 \mathrm{~mm} \times 200 \mathrm{~mm}$ & 49 & 1 & 49 \\
2 & $35 \mathrm{~mm} \times 35 \mathrm{~mm} \times 200 \mathrm{~mm}$ & 49 & 1 & 49 \\
3 & $40 \mathrm{~mm} \times 40 \mathrm{~mm} \times 200 \mathrm{~mm}$ & 25 & 2 & 50 \\
4 & $45 \mathrm{~mm} \times 45 \mathrm{~mm} \times 200 \mathrm{~mm}$ & 25 & 1 & 25 \\
5 & $50 \mathrm{~mm} \times 50 \mathrm{~mm} \times 200 \mathrm{~mm}$ & 25 & 1 & 25 \\
\hline
\end{tabular}

aThe three dimensions of the cuboid blocks.

${ }^{\mathrm{b}}$ The amount of cuboid blocks in one set.

'The amount of sets which composed by a certain number of cuboid blocks.

${ }^{\mathrm{d}}$ The amount of cuboid blocks which prepared for tests with a certain size.

Table 4. Experimental parameters and results of the artificial specimens with continuous orthogonal prefractures.

When simulating closed natural fractures, cement paste was used to glue neighboring small blocks to form a big cuboid block. And mechanical properties were obtained through standard test procedures. For the open natural fractures, the small blocks were left intact, and they were simply arranged according to the designed scheme. Then the big cuboid block was put in the central part of the metal mould, with the internal dimensions of $300 \mathrm{~mm} \times 300 \mathrm{~mm} \times 300 \mathrm{~mm}$. The cement paste between the small blocks was weaker than the small blocks, which can be seen as a group of continuous cemented fractures, perpendicular to each other. Figure 3 shows a schematic of the facture system.

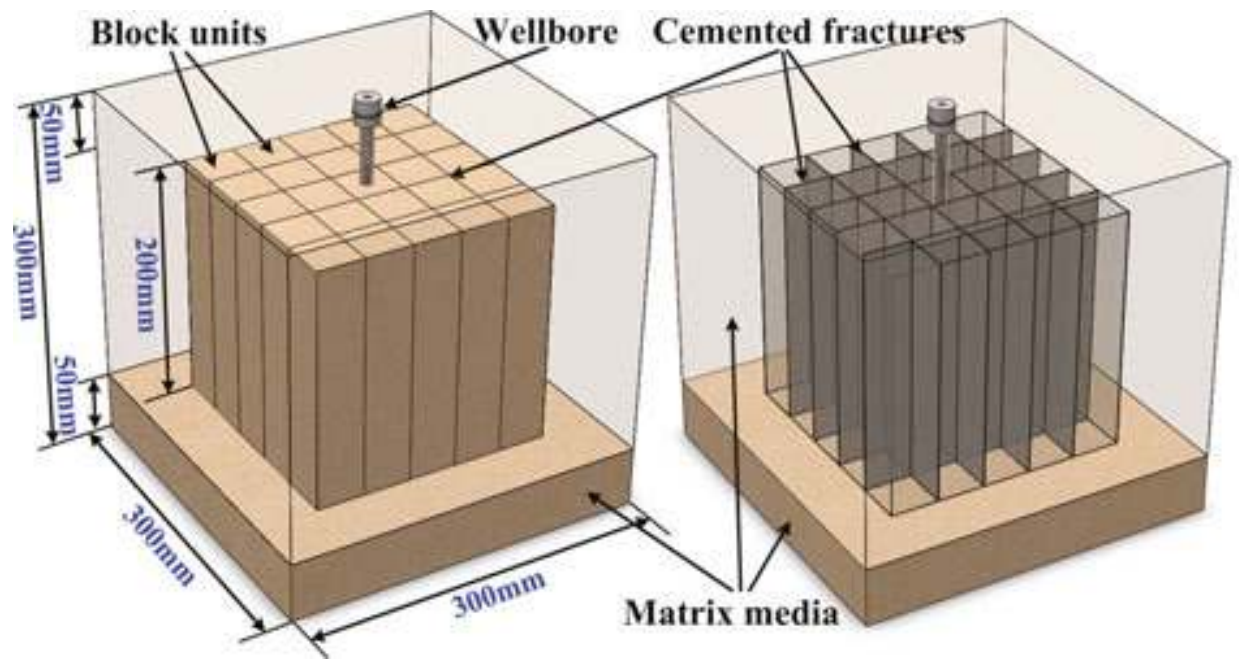

Figure 3. Schematics of the fracture system. 


\section{Results}

\subsection{Experiment results of coal}

The geometry of the hydraulic fractures was observed and analyzed by cutting the specimens after each test. The results showed a similar feature compared to that in naturally fractured rocks, however, hydraulic fractures in coal seam may initiate from opening cleats intersected by the wellbore.

\subsubsection{Initiation from cleats}

A main vertical fracture was usually observed along the maximum horizontal stress, as shown by specimen $\mathrm{C} 1$. And the fracture was also rather straight and planar overall. The fracture surface was quite rough (Figure 4(a)), caused by a large number of cleats and microfracture.
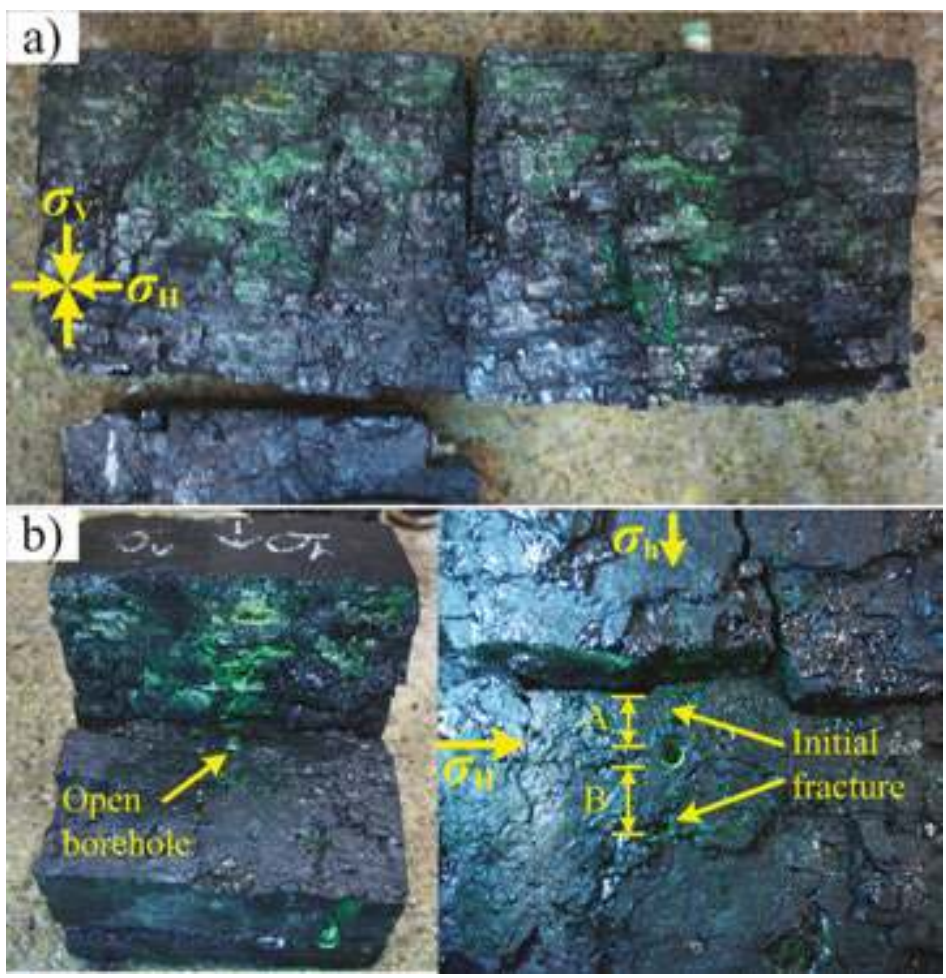

Figure 4. The main fracture (a) and cross-section (b) of specimen C1.

Figure 4(b) shows the photo of a specimen after testing. The specimen was split apart along the horizontal plane. And the vertical plane of the hydraulic fracture did not cross the borehole 
straight. The hydraulic fractures did not start along the maximum horizontal stress, instead the minimum horizontal stress direction was followed. Fracture section A met a face cleat when it was $30 \mathrm{~mm}$ away from the one side, then it coincided the face cleat. Fracture section B just propagated along its initial direction and did not meet any face cleats and the propagation halted after fracture section A connected the face cleat.

\subsubsection{Hydraulic fracture initiation in coal matrix}

In specimen $\mathrm{C} 2$, no cleats and cracks around the borehole were found, thus the hydraulic fracture started in the coal matrix along the maximum horizontal stress.

In Figure 5, the specimen was split for direct observation with the vertical main fracture of elliptic area along the maximum horizontal stress around the borehole. To the left, the hydraulic fracture met a face cleat about $60 \mathrm{~mm}$ away from the wellbore and then it extended along the face cleat surface until the boundary of the specimen was reached. To the right, the hydraulic fracture propagated approximately $90 \mathrm{~mm}$.

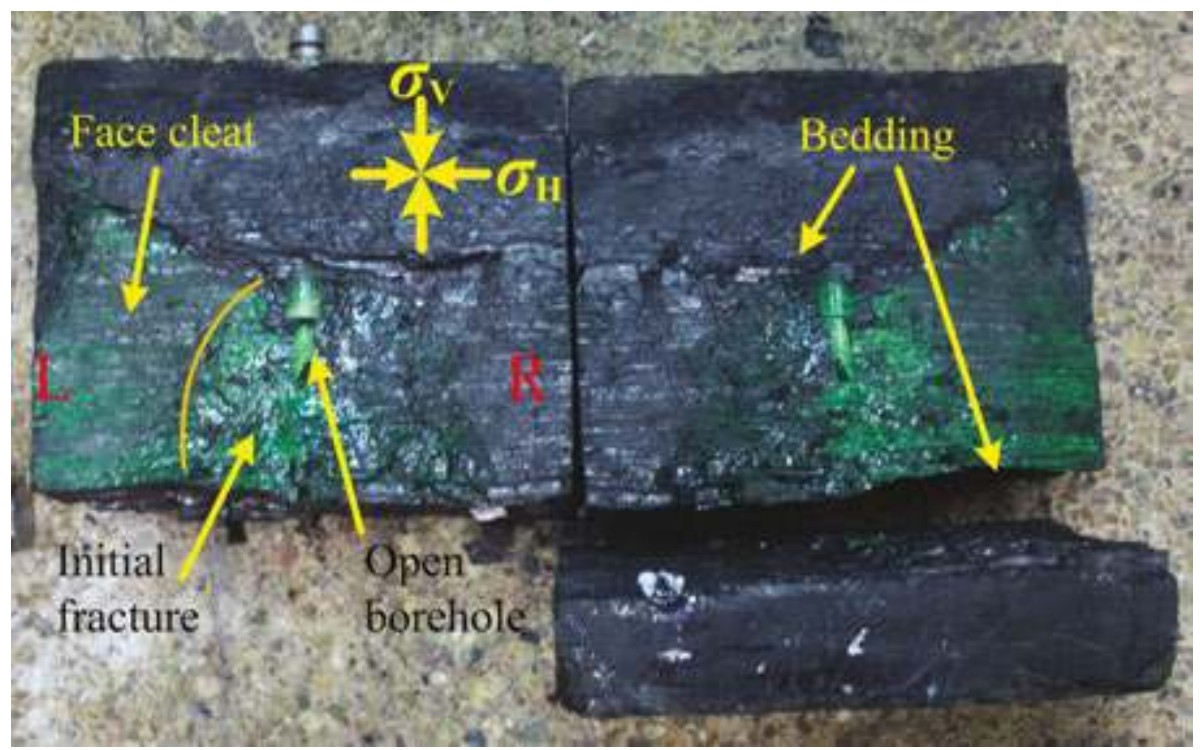

Figure 5. The controlled fracture of specimen C2.

The hydraulic fracture height was confined by bedding during propagation. The fractures were mainly distributed in the range of 60-200 $\mathrm{mm}$ away from the bottom of the specimen.

The fracture geometry characteristics of specimen C5 are almost the same as specimen C2, except that both wings of the fracture encountered the external surface and multiple fractures initiated at the borehole (see Figure 6). 


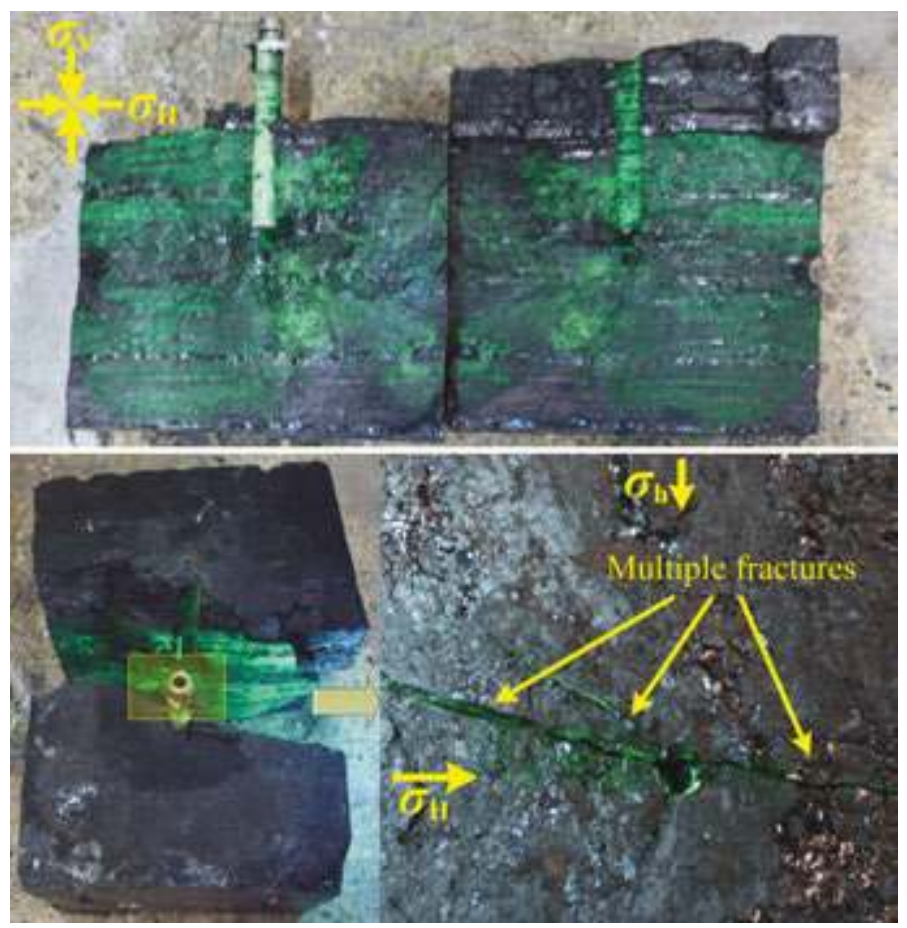

Figure 6. Multiple fractures around the borehole of specimen C5.

\subsubsection{Reorientation of hydraulic fractures}

When a vertical fracture initiates along the direction other than the maximum horizontal stress, the fracture will change its direction gradually to the maximum horizontal stress, due to strong control by the stress difference. Such phenomenon also was overserved in cases of hydraulic fracturing of coal seam tests.

The hydraulic fractures are shown in Figure 7 for specimen C3, after being opened along the horizontal directions. It was obverses that there was a hydraulic fracture of $\mathrm{S}$ shape.

At the upper part, there were two fractures which propagated initially subparallel and subsequently coincided into one fracture. Both fractures connected the cleats during reorientation. The hydraulic fracture ultimately turned to the maximum horizontal stress and reached the specimen boundary. At last, the width of the fracture network increased to $45 \mathrm{~mm}$.

At the lower part, there are three hydraulic fractures at the wellbore, one of which propagated $50 \mathrm{~mm}$, and the other two intersect a cleat and extend straight along the cleat to the specimen boundary. There is $59^{\circ}$ apart between the opened cleat and the maximum horizontal stress. 


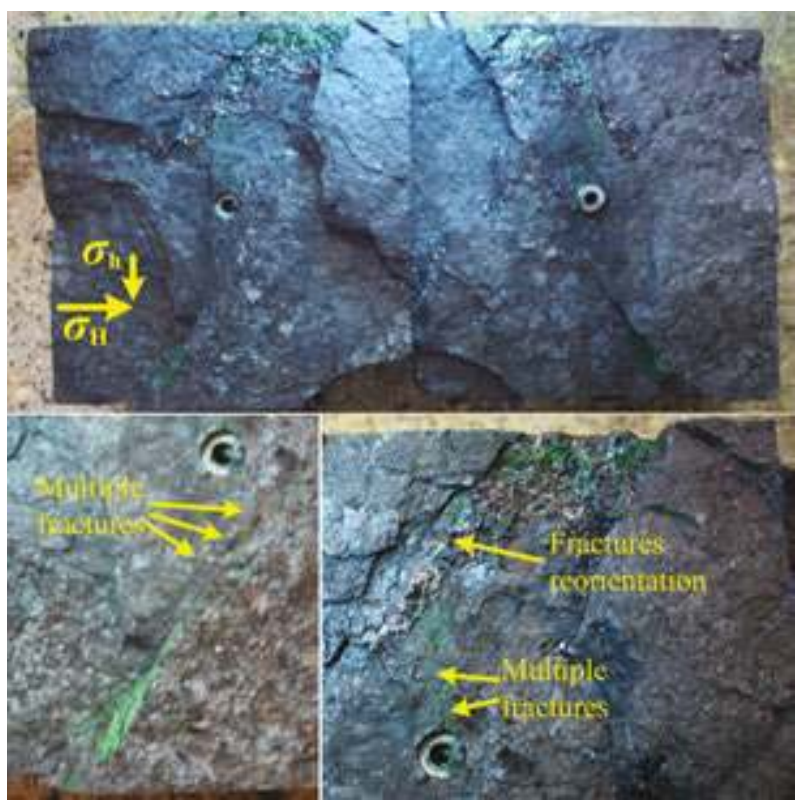

Figure 7. View of cross-section of specimen C3.

\subsubsection{The influence of cleats on hydraulic fractures}

The hydraulic fracturing of coal specimens shows complicated results, compared with the conventional single fracture. Usually, the specimens will be cut and split for visual examination

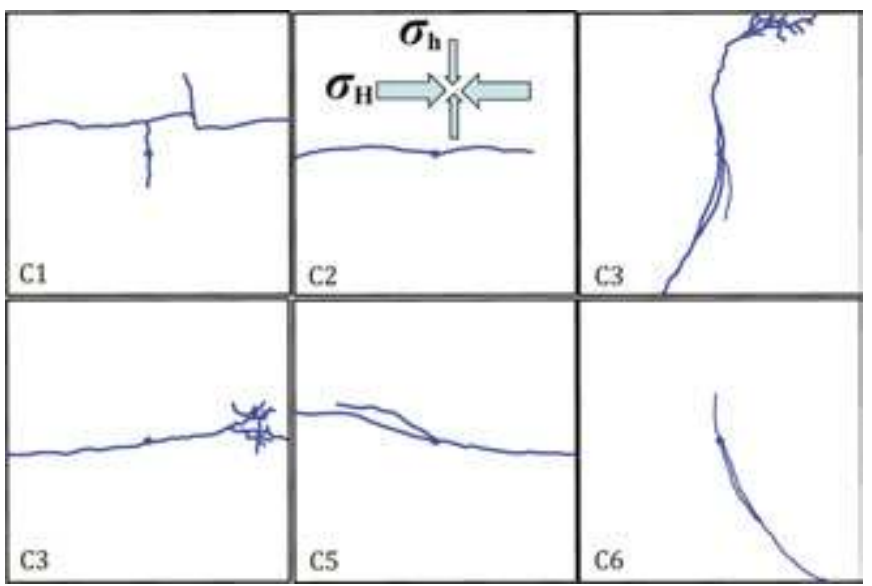

Figure 8. The distribution of the hydraulic fractures in the central horizontal plane for the tested specimens. 
of the hydraulic fractures. Figure 8 shows the hydraulic fracture patterns are very diverse, and they are not just a single planar fracture, but multiple fracture system connected to cleats.

The results of tests, in Figure 8, show that hydraulic fractures in coal seam can be started along directions other than the maximum horizontal stress. For example, hydraulic fractures could initiate from face or butt cleats, under the combined influences of stress state, coal mechanical properties, and borehole positions. There are three types of hydraulic fractures in coal seam.

Type 1. The hydraulic fracture extended along a face cleat (Figure 9). For example, type 1 includes specimen $\mathrm{C} 4$, where there is a long face cleat, intersecting the borehole. As in Table 1, the angle $\beta$ is $11^{\circ}$ and the hydraulic fracture started along an open cleat. Here, much low fluid pressure is required to open the cleat (Eq. (1)).

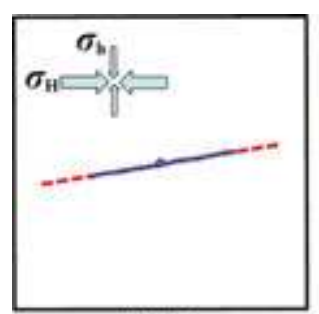

Type I

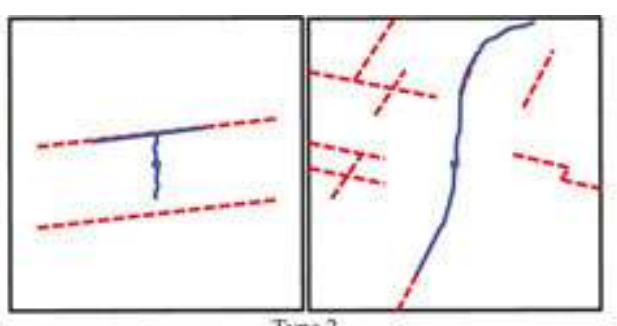

Type 2

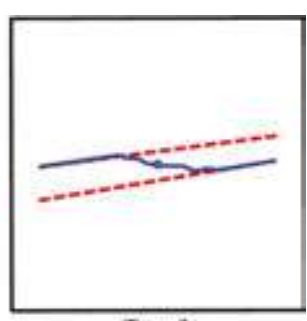

Type 3

Figure 9. The observed three possible types of hydraulic fracture initiation and propagation patterns.

$$
p_{\mathrm{b} 1}<p_{\mathrm{bE}}=3 \sigma_{\mathrm{h}}-\sigma_{\mathrm{H}}+\sigma_{\mathrm{t}}-p
$$

where $p_{\mathrm{b} 1}$ is the tested breakdown pressure for case 1 type systems; $p_{b E}$ is the breakdown pressure predicted by the elastic model [30]; $\sigma_{h}$ the minimum horizontal stress; $\sigma_{H}$ the maximum horizontal stress; $\sigma_{t}$ the tensile strength of coal; and $p$ the pore pressure. The breakdown pressure for specimen $\mathrm{C} 4$ is $8.8 \mathrm{MPa}$.

Type 2. The hydraulic fracture started inside a butt cleat, almost parallel to the minimum horizontal stress, then propagated along a face cleat (Figure 9, type 2), including specimens C1, C3, and C6. The fluid pressure in the wellbore is higher than the breakdown pressure of type 1 (Eq. (2)), and not sufficient to create a new fracture.

$$
p_{\mathrm{b} 1}<p_{\mathrm{b} 2}<p_{\mathrm{bE}}=3 \sigma_{\mathrm{h}}-\sigma_{\mathrm{H}}+\sigma_{\mathrm{t}}-p
$$

where $p_{\mathrm{b} 2}$ is the breakdown pressure for type 2 .

For type 2, a new fracture can form along $\sigma_{\mathrm{H}}$ much easier than those along $\sigma_{\mathrm{h}}$ to propagate, if $3 \sigma_{\mathrm{h}}-\sigma_{\mathrm{H}}+\sigma_{\mathrm{t}}<3 \sigma_{\mathrm{H}}-\sigma_{\mathrm{h}}$. 
Type 3. Figure 9 shows type 3 of fracture propagation (specimens C2 and C5), in which the hydraulic fracture initiated along the maximum stress, as depicted by hydraulic fracturing theory. If follows from Figure 9 that the hydraulic fracture tends to extend the cleat if the propagation direction is close to the maximum horizontal stress $\left(<20^{\circ}\right)$. Hubbert and Willis [30] proposed a breakdown pressure model for impermeable rocks (Eq. (3))

$$
p_{\mathrm{bE}}=3 \sigma_{\mathrm{h}}-\sigma_{\mathrm{H}}+\sigma_{\mathrm{t}}-p
$$

For type 3, it is known that:

$$
p_{\mathrm{b} 3}=p_{\mathrm{bE}}
$$

where $p_{\mathrm{b} 3}$ is the measured breakdown pressure for case of type 3 .

The pressure records during tests of specimens $C 2$ and $C 5$ give the breakdown pressure of 24.2 and $32.8 \mathrm{MPa}$. In our tests, pore pressure is not applied inside the specimens, and tensile strengths of 16.2 and $24.8 \mathrm{MPa}$ can be determined for coal.

The tensile strengths determined above are much greater than those reported (0.2-3.7 $\mathrm{MPa})$ for coal [31]. The reported tensile strengths were possibly obtained through rock mechanical tests (like Brazilian test or uniaxial tension test), with the specimens be limited in size, not many cleats included. As has been depicted for type 3, the tensile fracture initiated from the wellbore does not meet any cleats, implying initiation of hydraulic fracture on an intact surface. Furthermore, it has been recognized that coal shows significant scale effect, therefore the smallscale borehole (10 $\mathrm{mm}$ in diameter and $20 \mathrm{~mm}$ high) may also affect the tensile strength. Additional factors may contribute to the abnormal high breakdown pressures. However, there is currently insufficient research to address this question and it remains a topic for future investigation. Although the reason that our experiments derived such high tensile strengths is undetermined, it is evident that the breakdown pressure and derived tensile strength cannot be used directly at a field scale.

All of the above three types of hydraulic fracture initiation and propagation patterns indicate that the cleats near the borehole have a significant influence on the initiation of hydraulic fractures. When the fracturing fluid is continuously injected into the borehole and the fluid pressure is greater than the minimum fracture pressure of coal, cleats in coal open and probably leading to multiple hydraulic fractures near the borehole simultaneously. There may be uncertainty for the initial fracture orientation, and the final orientation is determined by cleat distribution and stress state. The initial fracture orientation is uncertain and determined by the distribution of the cleats on the borehole wall and the stress condition around the borehole. As the hydraulic fractures extend further, the number and appearance of the hydraulic fractures evolve, leading to multiple hydraulic fractures to the end.

There are many cleats in coal seam to be hydraulically fractured, which affect the propagation of hydraulic fractures. Following conventional hydraulic fracturing, the hydraulic fractures 
always extend along the maximum stress, where the least pressure is required. If cleats, in other directions, are connected by the hydraulic fractures, additional pressure is needed to prop those cleats, causing more cleats to be connected. At last, multiple hydraulic fractures will be induced, much like a network of hydraulic fractures in coal seam.

Since stress states are more responsible for the initiation and growth of the hydraulic fractures than cleats, the hydraulic fractures concentrate on a dominant direction, along with fracture branches of various complexities. If the approximate outline of such complex fractures in coal seam is made, an ellipse can be drawn on the horizontal plane, with the major axis following the maximum stress.

\subsection{Experiment results of shale}

\subsubsection{Combination of vertical and horizontal fracture}

Hydraulic fracturing experiments of shale specimens in laboratory were made to consider stress states, bedding, and natural fractures, and it is found that the hydraulic fractures of shales are usually combined by vertical, horizontal, and oblique fractures.

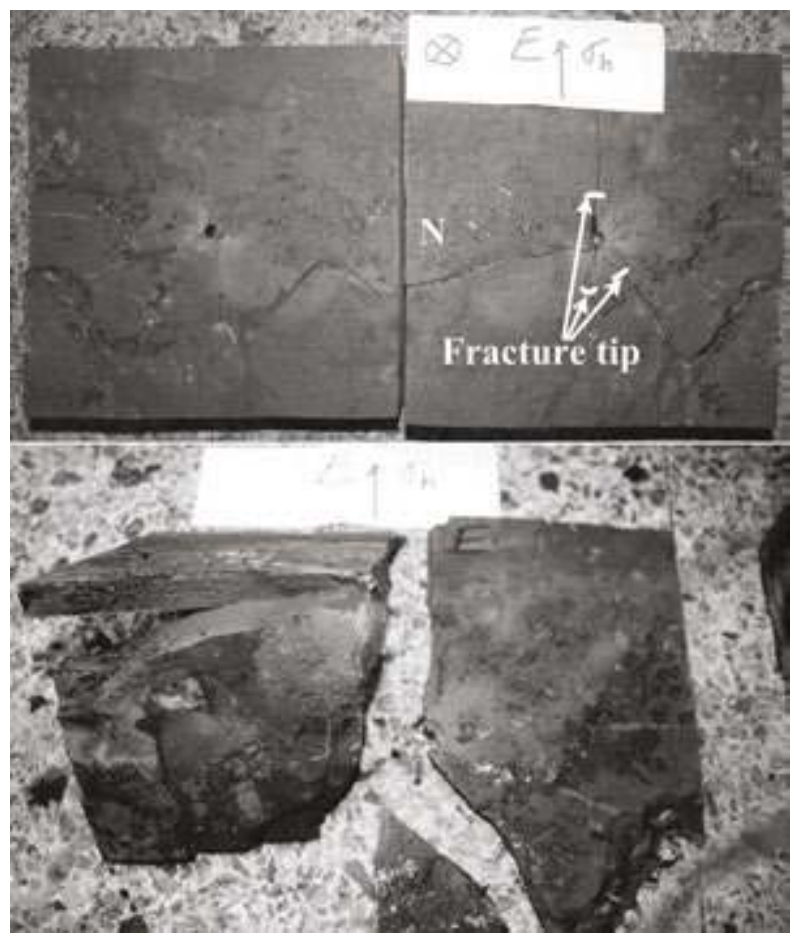

Figure 10. Hydraulic fractures of specimen S1. 
Specimen S1 of shale after hydraulic fracturing is outlined in Figure 10. There are two sets of hydraulic fractures as shown in Figure 10, one set being multiple vertical fractures of various shapes and orientations. It is conceivable that one long fracture extends along the maximum horizontal stress, and three other small fractures along the minimum horizontal stress. The other set of hydraulic fractures in shale is following the beddings, or horizontal hydraulic fractures. It is not clear to tell how such fracture system developed in time only by visual checking the final fractures.

It is reasonable to postulate the possibilities of initiation and propagations of the multiple vertical and horizontal fractures. The hydraulic fractures are vertical on the wellbore at the beginning and extend to reach the beddings, where hydraulic fractures deviate from planar vertical to horizontal, and the beddings' effect becomes obvious.
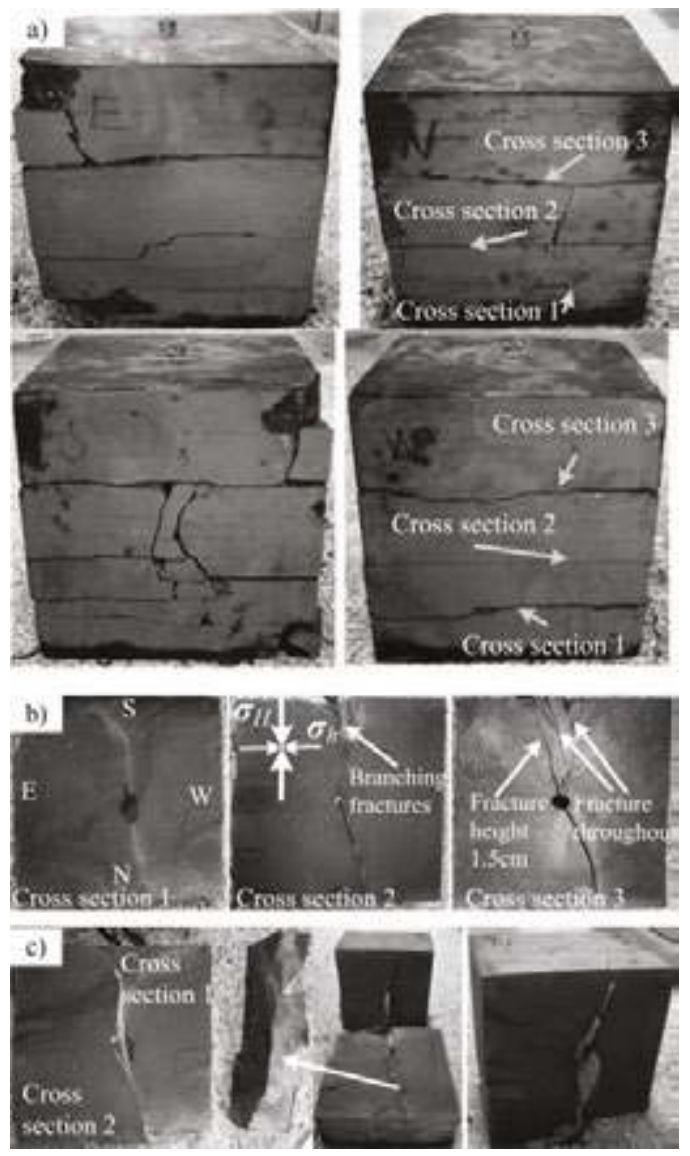

Figure 11. (a) The outside surfaces of specimen S2; (b) view of each cross-section; (c) the multifracture between crosssection 1 and cross-section 2. 


\subsubsection{Multiple hydraulic fractures}

Multiple hydraulic fractures are also observed, shown in Figure 11. Along the beddings and horizontal fractures, the specimens are disintegrated for specifying hydraulic fractures. As depicted in Figure 11, fracture extension tends to extend in the maximum horizontal stress, in accordance with the least resistance. However, in south and north directions, there are multiple fractures, with much closely-spaced multiple fractures in the north direction. And the hydraulic fractures in the south are radiating from the wellbore and become subparallel later up to the side of the specimen, about $30 \mathrm{~mm}$ apart.

The hydraulic fractures in the north are sub-parallel with the maximum horizontal stress, with $20^{\circ}$ of angle. Currently, stimulated reservoir volume is becoming popular in industry, especially in shale and tight reservoir stimulations, and we believe that the hydraulic fractures in shale specimens can be an indicator for evidence.

\subsubsection{Oblique hydraulic fractures}

In the fracturing experiments of shales, other than vertical, horizontal, and multiple fractures, twisted oblique fractures are also present, shown in specimen S3.

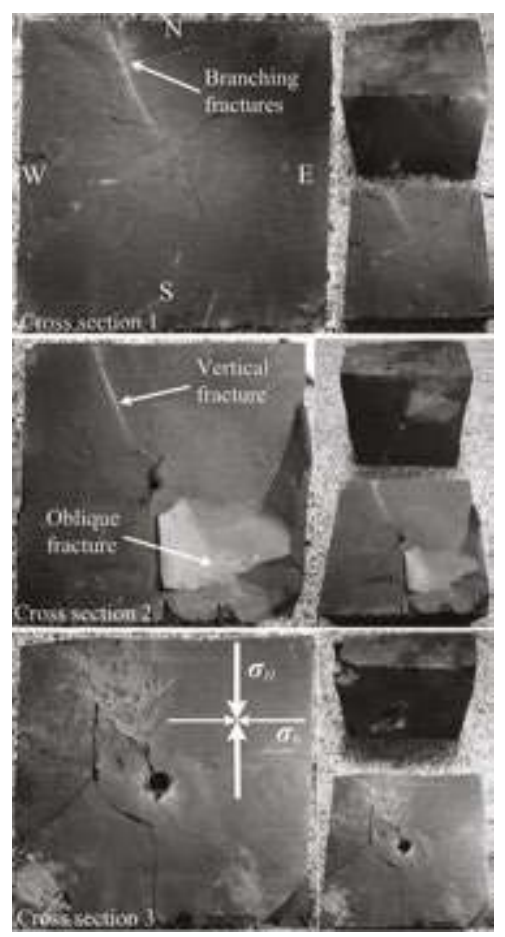

Figure 12. View of each cross-section of specimen S3. 
In Figures 12 and 13, along the fractured faces, specimen S3 is pull apart for observation. On cross-section 1, branched fractures appear along N-W directions; on cross-section 2, subvertical fracture and oblique fracture occur simultaneously. And cross-section 3 shows a horizontal fracture along the bedding. The most distinct result is found from the south direction, characterized by a curved surface of hydraulic fractures, originated from the well bore, extended outward in S shape.

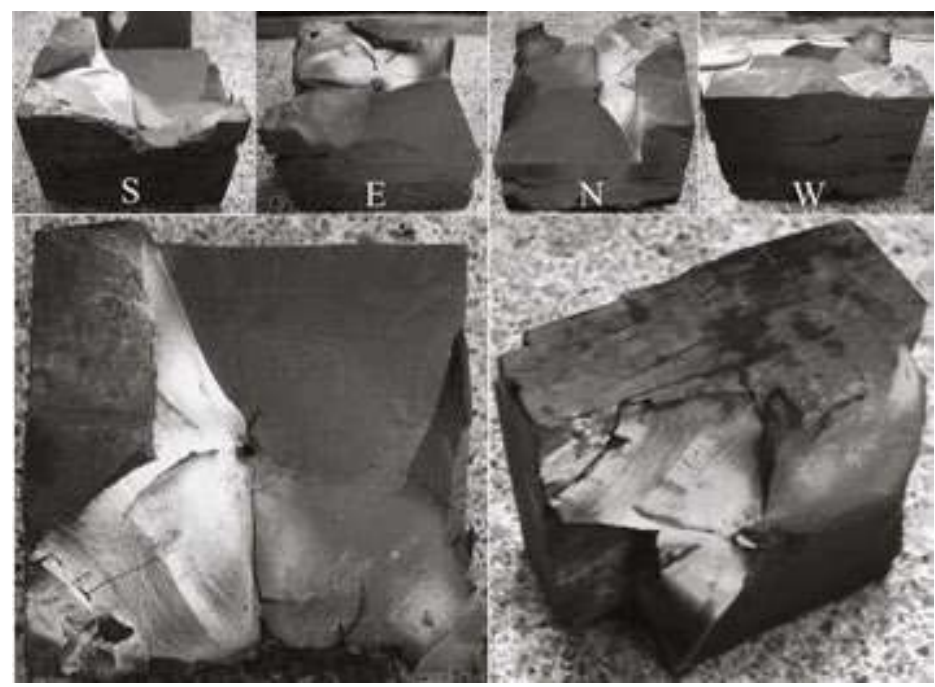

Figure 13. The oblique fracture between cross-section 2 and cross-section 3.

\subsection{Experiment results of artificial specimens}

In this part, we used cementation specimens in the experiment, for apparent reasons of easy preparation of specimens of various natural fractures. Emphasis is put on natural fracture density and the injection rate.

\subsubsection{Hydraulic fractures of artificial specimens}

The direct observation of the hydraulic fractures can provide useful information on the influences of testing conditions. As in Figure 14, the specimen can be split easily along the natural fracture for the cases of orthogonal natural fractures.

\section{Spatial configuration of hydraulic fractures}

The projections of the hydraulic fractures in the horizontal plane are shown in Figure $\mathbf{1 5}$. Figure 15 shows that the hydraulic fractures are interconnected by the natural fractures, and their dimensions varied with locations. The overall affected zone by hydraulic fractures appears to be a horizontal ellipse. 

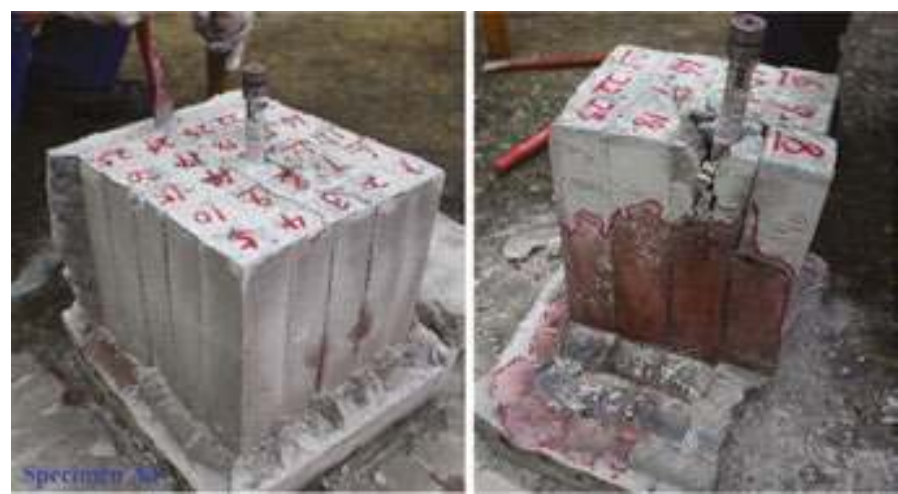

Figure 14. Dismantled specimen.

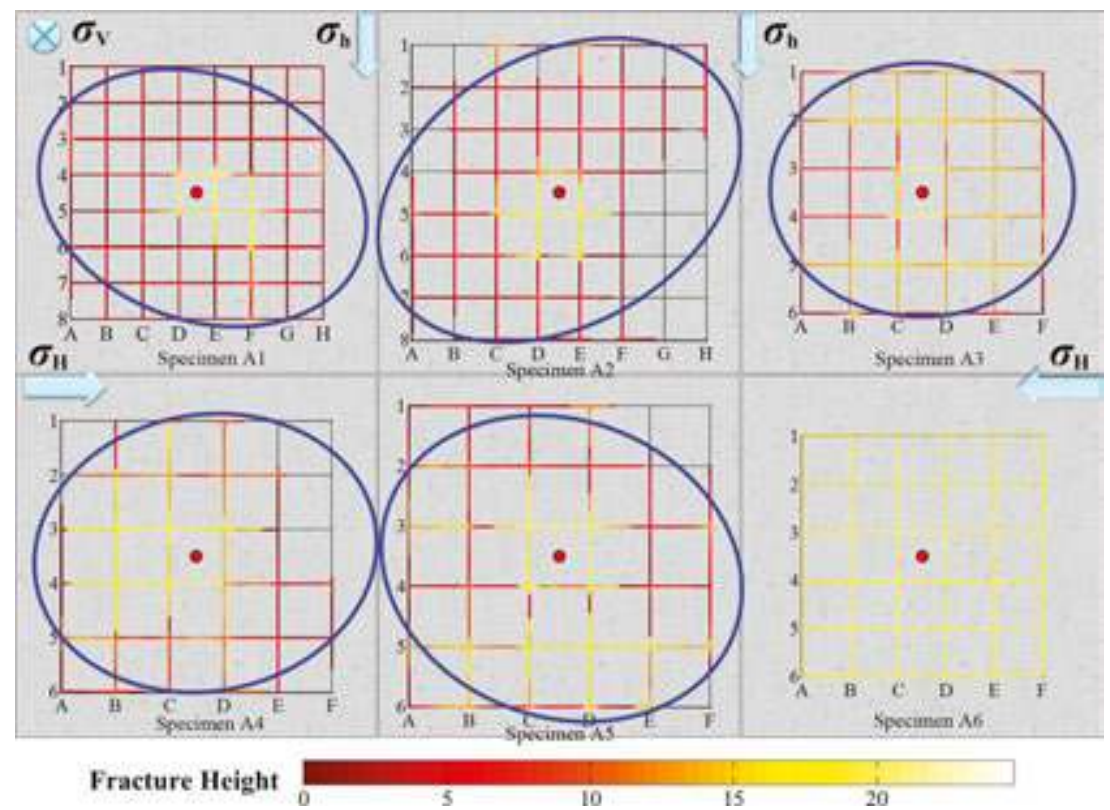

Figure 15. Height variation by projection onto the horizontal plane.

The major axis of the fracture swarm ellipsis is not the same as the maximum horizontal stress and the fracture height decreases gradually away from the wellbore, as shown in specimens A1-A5. In accordance with the conventional fracturing, in a homogeneous formation the hydraulic fracture is a planar along the maximum horizontal stress. And the major axis is not along the maximum stress in our experiments, implying that the natural fractures have apparent effects on the hydraulic fractures, through stress redistribution. 


\section{Area of hydraulic fractures}

The hydraulic fractures are composed of a system of complicated branched fractures, and it is not easy to have a simple calculation for area of hydraulic fractures, each of which varies with locations in terms of length and height. In the calculation of areas, a process of scanning and digitization is employed to get an entire spatial geometry of the fracture network, as in Figure 16. The fracture set 1 (fractures $1,2,3 \ldots$ ) and fracture set 2 are parallel to the maximum and minimum stresses, respectively.

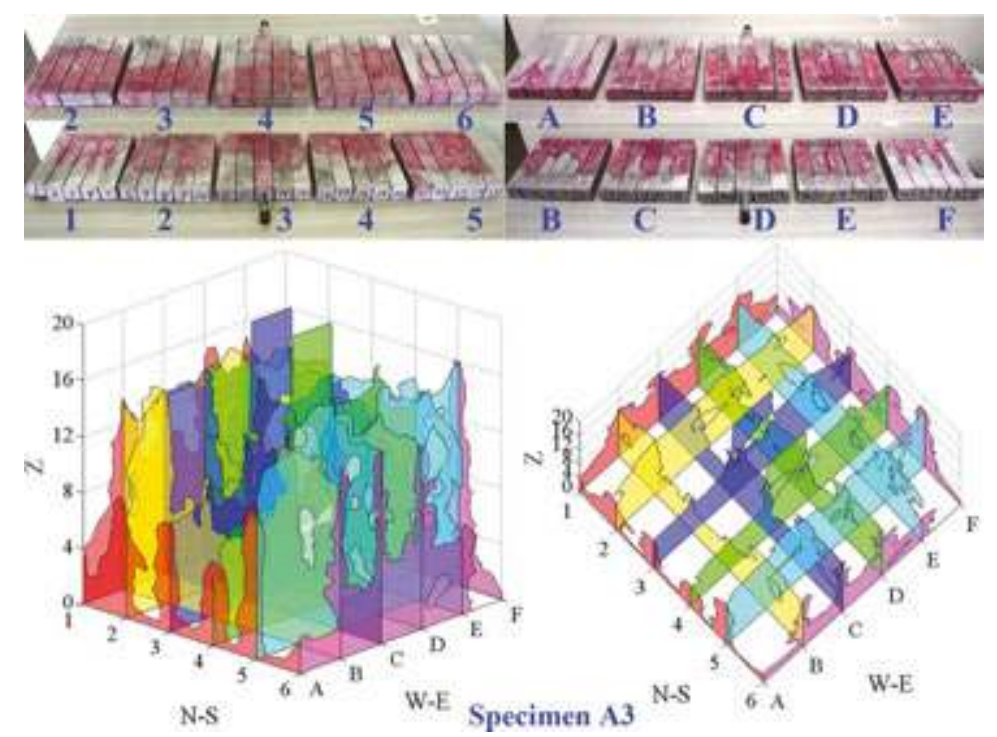

Figure 16. The geometry of the hydraulic fracture network in 3D space.

The final shape of multiple fracture system created in tests of natural fractured blocks, show an approximate ellipsoid envelope, with three orthogonal axes, in which the major one corresponding to fracture length along the maximum horizontal stress, the minor one corresponding to fracture width along the minimum horizontal stress, and the third one along the vertical direction. Such an ellipsoid embraces two groups of hydraulically induced fractures, most of which are along the natural fracture. And the three orthogonal axes are not exactly along the stress directions, i.e., there are some deviations between stress directions and the three orthogonal axes. This means that both in-situ stress state and multiple natural fractures determine the hydraulic fracture network at the same time.

Due to the weak cementation of the natural fractures, the hydraulic fractures mainly extend in the natural fractures, and at the beginning the hydraulic fracture started in the central block (no. 25 in specimens A1 and A2 and as no. 13 in specimens A3-A6, in Figure 17). Different from single hydraulic fracture, a complicated hydraulic fracture network results. 


\begin{tabular}{|c|c|c|c|c|c|c|c|c|c|}
\hline & & & & & $\mathbf{N}$ & & & & \\
\hline & $\mathrm{A}^{\mathrm{A}}$ & B & C & & & f & $F$ & ; & \\
\hline & & & 2 & 3 & 4 & 5 & 6 & 7 & \\
\hline & 8 & & 9 & 10 & 11 & 12 & 13 & 14 & \\
\hline & I & & 16 & 17 & 18 & 19 & 20 & 21 & \\
\hline $\mathbf{w}$ & 2 & & 23 & 24 & 25 & 26 & 27 & 28 & $\boldsymbol{E}$ \\
\hline & 2 & & 30 & 31 & 32 & 33 & 34 & 35 & \\
\hline & 3 & & 37. & 38 & 39 & 40 & 4] & 42 & \\
\hline & 4 & & 44 & 45 & 46 & 47 & 48 & 49 & \\
\hline
\end{tabular}
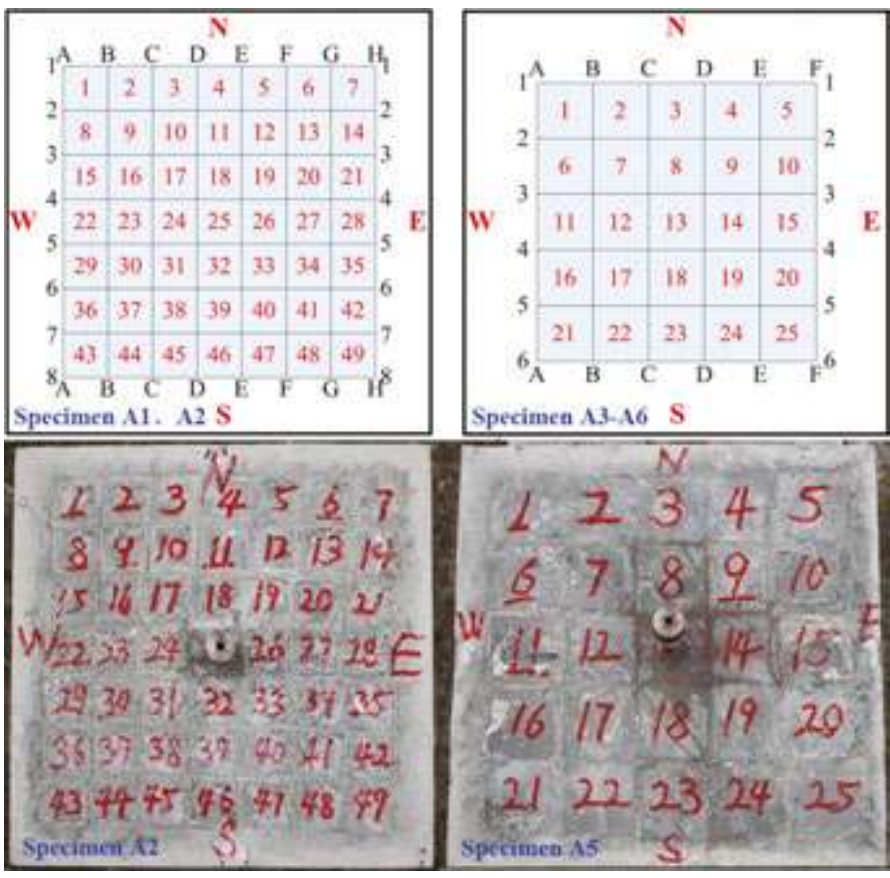

Figure 17. Block units and cemented fractures with numbers on the top of the specimens. (Notes: numbers in red are block units, letters in red are the orientation of the specimens, and those in black are cemented fractures).

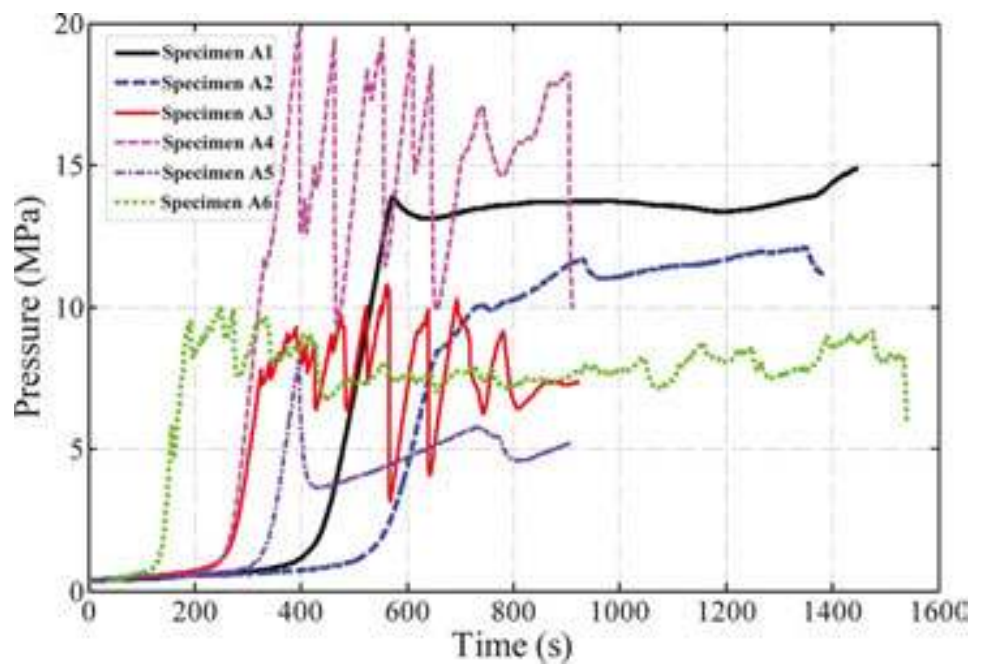

Figure 18. Injection pressure versus time for the specimens. 
Here, we present the physical explanation on the possible fracture extension process in the natural fractured blocks, because it is difficult to conduct an accurate measurement of the initiation of fracture growth in a routine test. And in the next paragraph, will discuss to characterize fractures by acoustic emission. In testing of specimen A3 as no. 13 in the upper right quadrant of Figure 17, a vertical fracture initiated in the central block, and extended along E-W direction until the natural fractures $C$ and $D$ were encountered, with the fracture tips touching the adjacent bounders of blocks 12 and 14, and no obvious penetration. Such observation can imply the hydraulic fractures became blunt when intersecting with natural fracture $C$ or $D$, and then fracture propagation paused for $10 \mathrm{~s}$. The rapid drop of fluid pressure (Figure 18) also confirmed the assumed behavior of hydraulic fracture, indicating the initiation of a hydraulic fracture or shear slipping between both fracture faces.

Acoustic emission was used to locate breaking events, caused during rock failures in hydraulic fracturing. It was applied in fields to provide real-time fracture propagation in terms of length and height [32-35]. There are also many different arguments for or against the mechanism of acoustic emission for locating failure events. Rock failures can be roughly categories into two types, tensile, and shear failures. There is no consensus that acoustic receivers collect tensile or shear failures, however, tensile and shear failures both emit acoustic signals. Shear slippage caused by injection of water pressure is a process of a local stress redistribution, which could accommodate fracture branching or dendritic. Many fracture branches at different locations could lead to a volume of reservoir stimulation, with each local failure indicating an acoustic emission.

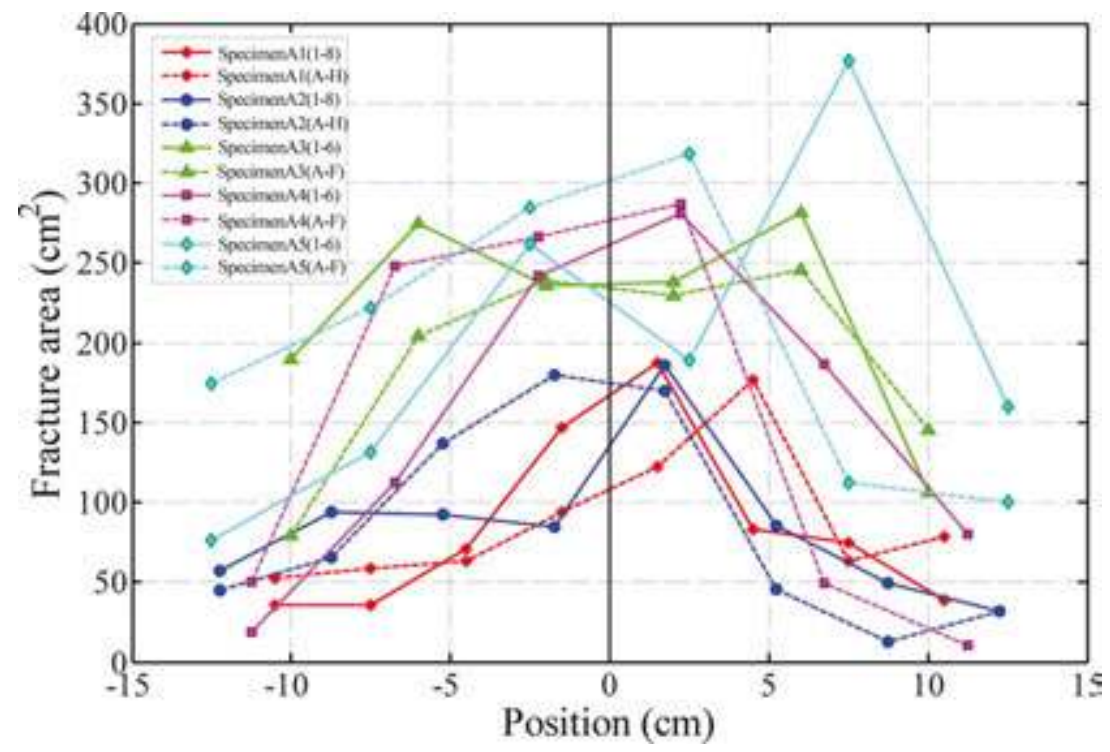

Figure 19. Variations of the hydraulic fracture areas with their positions. (The origin is located on the borehole axis, north to south and west to east is positive.) 
In order to calculate the area and the geometry of the fractures, the area of each hydraulic fracture swept by dyed fracturing fluid. In Figure 19, the fracture areas for specimens A1-A5 after tests are shown. In our tests, all hydraulically induced fractures are along the natural fracture, due to weak mechanical properties of natural fractures.

Next, the calculated total fracture area was compared with the total volumes of injected fluid. Figure 20 depicted the relationship between the total fracture area and the total volumes, and it was shown that the total fracture areas of specimens A1 and A2 are less than others, even though the total volumes of injected fluid were quite similar. In our tests, the permeability of all specimens are very slight, then the specimens A1 and A2 are much wider than those of specimens A3, A4, and A5, based on material balance.

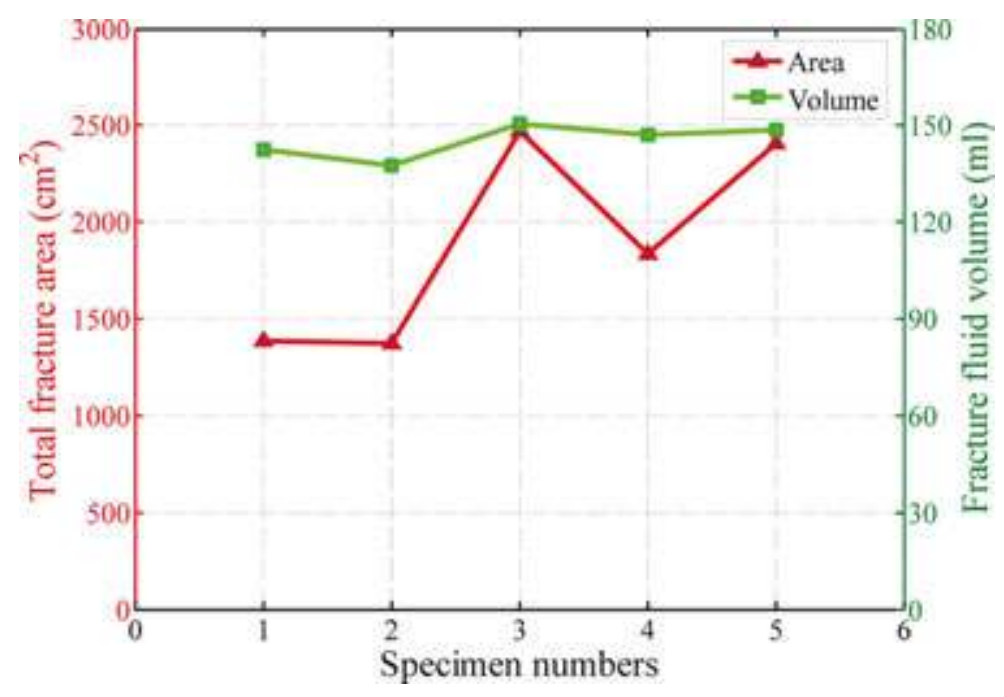

Figure 20. Hydraulic fracture area and injection fluid volume of each specimen.

\subsubsection{Influences of natural fracture and injection rate}

Figure 18 shows the pressure records of all the six specimens. These records can be classified into two types according to the fluctuation features: (1) The pressure records changed very slowly and smoothly (specimens A1 and A2) after initiation. (2) The injection pressure changed abruptly in the entire process (specimens A3, A4, A5, and A6). It can be attributed to the influences of both the natural fracture and the injection rate.

\section{(1) Natural fracture}

Pressure records can be seen as a measure of the influences of fracture density on fracture propagation. From Figure 18, it seems that the extension pressure of specimens A1 and A2 are greater than $\mathrm{A} 3$ and $\mathrm{A} 5$, less than specimen $\mathrm{A} 4$. 
Firstly, for rate of $0.1 \mathrm{ml} / \mathrm{s}$, the total fracture areas and injection fluid volumes are quite close for specimens A1 and A2, however, the extension pressure of specimen A1 (13.63 MPa) is much higher than that of specimen A2 (11.28 MPa) (Figure 21a). Such difference can reflect that fracture spacing affects the interaction between multiple fractures. When fracture opens, it will exert additional stresses on the neighboring fractures, so less fracture spacing can improve fracture interference. Figure $\mathbf{2 1 b}$ for specimens A3 and A5 show the same results.

In Figure 21, the extension pressure of specimen A4 was much higher than expected. The cementation between failed fracture faces is still strong, in specimen A4. Stronger cementation applies more restriction on fracture extension.

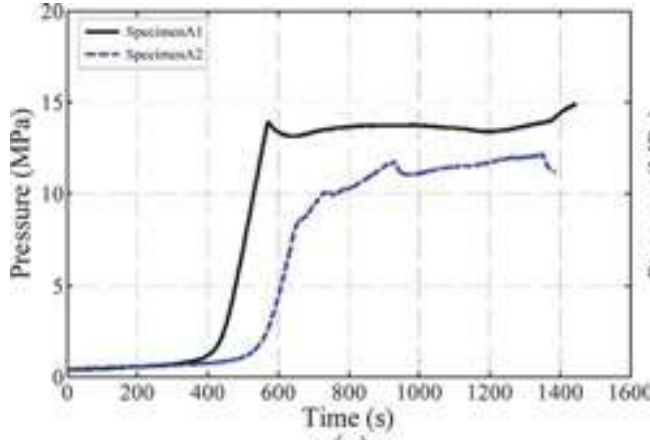

(a)

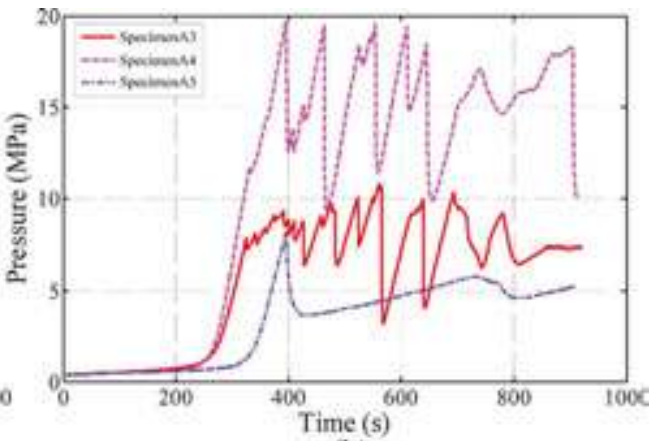

(b)

Figure 21. Injection pressure records: (a) injection rate $0.10 \mathrm{ml} / \mathrm{s}$, (b) injection rate $0.16 \mathrm{ml} / \mathrm{s}$.

\section{(2) Influences of injection rates}

The pressure records can also as the indication of changes in injection rate, and then some useful information can be obtained from response pressure caused by injection rate.

If the injection rate is less than $0.1 \mathrm{ml} / \mathrm{s}$, in Figure 18, changes in flow rate do not cause great change in extension pressure.

However, if the injection rate is high (up to $0.16 \mathrm{ml} / \mathrm{s}$ ), changes in extension pressure are frequent and great.

If the injection rate is higher than $0.33 \mathrm{ml} / \mathrm{s}$, the changes in extension pressure is more frequent, however is more mild.

The laboratory tests show that injection rate can influence the extension pressure to a great degree. The extension pressure can become more frequent.

\subsection{Result comparisons}

Laboratory experiments are conducted with three types of rocks: coal seam, shale, and artificial rock, which include natural fractures or simulated natural fractures. It is found that natural 
fractures play an important role in hydraulic fracturing. Hydraulic fractures always extend and follow the natural fractures, since natural fractures in rocks usually are weaker in mechanical properties than rocks. However, it seems the difference between natural fractures and rocks also affect the behavior of hydraulic fracturing. The mechanical properties of coal seam, artificial rock, and shale become stronger, so it is much easier for hydraulic fractures in shale to follow the natural fractures, and in coal seams, hydraulic fractures not only follow the natural fractures, but also extend in coal matrix.

\section{Conclusions}

Natural fractures are complicated, composed of multiple cracks of different origins and mechanical properties. Usually, the cracks or natural fractures are weak in mechanical properties. And natural fractures present themselves in various configurations. In coal seams, two orthogonal groups of natural fractures, butt and face cleats, determine the overall properties of coals. In shales, natural fractures are distributed more or less at random, filled with minerals or open, mostly controlled by geological processes. For artificial rocks, natural fractures can be designed in terms of geometrical and mechanical properties.

In this chapter, laboratory tests were conducted, with three rocks with natural fractures. Even though the rocks are different, shales, coals, and artificial rocks, experiments suggested a strong influence of natural fractures and injection rates.

The process of hydraulic fracture networks is definitely complex, however, in our laboratory tests we can infer from our testing data that hydraulic fracture networks are caused by interaction between hydraulic fracturing and natural fractures.

(1) Cleats, the natural fractures in coal seam, have significant influence on hydraulic fracture initiation. Because of low strength of cleats, hydraulic fracture in most cases takes the extension path as the cleats. So, stress state underground and cleat parameters can affect the interactive process of natural fractures and hydraulic fractures.

(2) Hydraulic fractures in shale in laboratory can be vertical, horizontal, or combinations of both cases. And we can infer that the stimulated reservoir volume in shale can be seen as a group of different hydraulic fractures, and much of which are augmented by the natural fractures.

(3) Based on influences of stress difference and natural fracture directions on hydraulic fractures, the conditions for hydraulic fracture crossing the natural fractures can be obtained experimentally as $\Delta \theta=90^{\circ} / \Delta \sigma \geq 2 \mathrm{MPa}$ are $\Delta \theta=60^{\circ} / \Delta \sigma \geq 4 \mathrm{MPa}$.

(4) Hydraulic fractures, or stimulated reservoir volumes, is the combined effects of reopening of natural fractures and interaction between hydraulic fracture and natural fractures. In naturally fractured formations, fracture network can be characterized by a three dimensional ellipsoid, with its three axes being aligned the orthogonal stresses approximately, but the deviation can be substantial. 


\section{Author details}

Guangqing Zhang* and Tiegang Fan

*Address all correspondence to: zhangguangqing@cup.edu.cn

Department of Engineering Mechanics, China University of Petroleum in Beijing, Beijing, China

\section{References}

[1] Lamont N, Jessen FW. The effects of existing fractures in rocks on the extension of hydraulic fractures. Journal of Petroleum Technology. 1963;5(2):203-209. DOI: 10.2118/419-PA.

[2] Blanton TL. An experimental study of interaction between hydraulically induced and pre-existing fractures. In: SPE Unconventional Gas Recovery Symposium; 16-18 May 1982; Pittsburgh, Pennsylvania. Society of Petroleum Engineers; 1982. p. 559-571. DOI: 10.2118/10847-MS.

[3] Warpinski NR, Teufel LW. Influence of geologic discontinuities on hydraulic fracture propagation (includes associated papers 17011 and 17074). Journal of Petroleum Technology. 1987;39(2):209-220. DOI: 10.2118/13224-PA.

[4] Zhou J, Chen M, Jin Y, Zhang GQ. Analysis of fracture propagation behavior and fracture geometry using a tri-axial fracturing system in naturally fractured reservoirs. International Journal of Rock Mechanics and Mining Sciences. 2008;45(7):1143-1152. DOI: 10.1016/j.ijrmms.2008.01.001.

[5] Athavale AS, Miskimins JL. Laboratory hydraulic fracturing tests on small homogeneous and laminated blocks. In: 42nd US Rock Mechanics Symposium and 2nd USCanada Rock Mechanics Symposium; 29 June-2 July; San Francisco, California. American Rock Mechanics Association; 2008.

[6] Jeffrey RG, Zhang X, Thiercelin MJ. Hydraulic fracture offsetting in naturally fractured reservoirs: quantifying a long-recognized process. In: SPE Hydraulic Fracturing Technology Conference; 19-21 January 2009; The Woodlands, Texas. Society of Petroleum Engineers; 2009. p. 1-15. DOI: 10.2118/119351-MS.

[7] Rahman MM, Aghighi MA, Shaik AR. Numerical modelling of fully coupled hydraulic fracture propagation in naturally fractured poro-elastic reservoirs. In: EUROPEC/ EAGE Conference and Exhibition; 8-11 June 2009; Amsterdam, The Netherlands. Society of Petroleum Engineers; 2009. p. 1-7. DOI: 10.2118/121903-MS. 
[8] Dahi Taleghani A. Analysis of hydraulic fracture propagation in fractured reservoirs: an improved model for the interaction between induced and natural fractures [Ph.D. dissertation]. Texas, United States: The University of Texas at Austin; 2009.

[9] Chuprakov DA, Akulich A, Siebrits E, Thiercelin MJ. Hydraulic fracture propagation in a naturally fractured reservoir. In: SPE Oil and Gas India Conference and Exhibition; 2010; Mumbai, India. Society of Petroleum Engineers; 2010. p. 1-12. DOI: 10.2118/128715-PA.

[10] McLennan JD, Tran DT, Zhao N, Thakur SV, Deo MD, Gil IR, et al. Modeling fluid invasion and hydraulic fracture propagation in naturally fractured formations: a threedimensional approach. In: SPE International Symposium and Exhibition on Formation Damage Control; 10-12 February 2010; Lafayette, Louisiana, USA. Society of Petroleum Engineers; 2010. p. 1-13. DOI: 10.2118/127888-MS.

[11] Min KS, Zhang Z, Ghassemi A. Numerical analysis of multiple fracture propagation in heterogeneous rock. In: 44th US Rock Mechanics Symposium and 5th US-Canada Rock Mechanics Symposium; 27-30 June 2010; Salt Lake City, Utah. American Rock Mechanics Association; 2010. p. 1-10. DOI: 10.2118/127888-MS.

[12] Akulich AV, Zvyagin AV. Interaction between hydraulic and natural fractures. Fluid Dynamics 2008;43(3):428-435. DOI: 10.1134/S0015462808030101.

[13] Potluri NK, Zhu D, Hill AD. Effect of natural fractures on hydraulic fracture propagation. In: SPE European Formation Damage Conference; 25-27 May 2005; Sheveningen, The Netherlands. Society of Petroleum Engineers; 2005. p. 1-6. DOI: 10.2118/94568-MS.

[14] Zhang X, Jeffrey RG. Thiercelin M. Deflection and propagation of fluid-driven fractures at frictional bedding interfaces: a numerical investigation. Journal of Structural Geology. 2007;29(3):396-410. DOI: 10.1016/j.jsg.2006.09.013.

[15] Daneshy AA. Hydraulic fracture propagation in the presence of planes of weakness. In: SPE European Spring Meeting; 29-30 May 1974; Amsterdam, Netherlands. Society of Petroleum Engineers; 1974. p. 1-8. DOI: 10.2118/4852-MS.

[16] Stadulis JM. Development of a completion design to control screenouts caused by multiple near-wellbore fractures. In: Low Permeability Reservoirs Symposium; 19-22 March 1995; Denver, Colorado; 1995. Copyright 1995, Society of Petroleum Engineers, Inc.; 1995. p. 69-84. DOI: 10.2118/29549-MS.

[17] Britt LK, Hager CJ, Thompson JW. Hydraulic fracturing in a naturally fractured reservoir. In: International Petroleum Conference and Exhibition of Mexico; 10-13 October 1994; Veracruz, Mexico. Society of Petroleum Engineers; 1994. p. 483-492. DOI: 10.2118/28717-MS.

[18] Rodgerson JL. Impact of natural fractures in hydraulic fracturing of tight gas sands. In: SPE Permian Basin Oil and Gas Recovery Conference; 21-23 March 2000; Midland, Texas. Society of Petroleum Engineers; 2000. p. 1-9. DOI: 10.2118/59540-MS. 
[19] Jeffrey RG, Zhang X, Bunger AP. Hydraulic fracturing of naturally fractured reservoirs. In: Thirty-fifth Workshop on Geothermal Reservoir Engineering; February 1-3, 2010; Stanford University, Stanford, California.

[20] Blanton TL. Propagation of hydraulically and dynamically induced fractures in naturally fractured reservoirs. In: SPE Unconventional Gas Technology Symposium; 18-21 May 1986; SPE Unconventional Gas Technology Symposium. Society of Petroleum Engineers; 1986. p. 613-627. DOI: 10.2118/15261-MS.

[21] Renshaw CE, Pollard DD. An experimentally verified criterion for propagation across unbonded frictional interfaces in brittle, linear elastic materials. International Journal of Rock Mechanics and Mining Science \& Geomechanics. 1995;32(2):237-249. DOI: 10.1016/0148-9062(94)00037-4.

[22] De Pater CJ, Beugelsdijk LJL. Experiments and numerical simulation of hydraulic fracturing in naturally fractured rock. In: Alaska Rocks 2005, The 40th U.S. Symposium on Rock Mechanics (USRMS); 25-29 June 2005; Anchorage, Alaska. American Rock Mechanics Association; 2005.

[23] Zhou J, Xue C. Experimental investigation of fracture interaction between natural fractures and hydraulic fracture in naturally fractured reservoirs. In: SPE EUROPEC/EAGE Annual Conference and Exhibition; 23-26 May 2011; Vienna, Austria. Society of Petroleum Engineers; 2011. p. 1-12. DOI: 10.2118/142890-MS.

[24] Olson JE, Bahorich B, Holder J. Examining hydraulic fracture: natural fracture interaction in hydrostone block experiments. In: SPE Hydraulic Fracturing Technology Conference; 6-8 February 2012; The Woodlands, Texas. Society of Petroleum Engineers; 2012. p. 1-10. DOI: 10.2118/152618-MS.

[25] La Pointe PR, Hudson JA. Characterization and interpretation of rock mass joint patterns. Geological Society of America Special Papers. 1985;199:1-38. DOI: 10.1130/ SPE199-p1.

[26] Lachenbruch AH. Depth and spacing of tension cracks. Journal of Geophysical Research. 1961;66(12):4273-4292. DOI: 10.1029/JZ066i012p04273.

[27] Laubach SE, Marrett RA, Olson JE, et al. Characteristics and origins of coal cleat: a review. International Journal of Coal Geology. 1998;35(1-4):175-207. DOI: 10.1016/ S0166-5162(97)00012-8.

[28] Dron RW. Notes on cleat in the Scottish coalfield. Transactions of the Institute of Mining Engineers. 1925;70:115-117. DOI: 10.1016/S0166-5162(97)00012-8.

[29] Kim CM and Abass HH. Hydraulic fracture initiation from horizontal wellbores: laboratory experiments. In: The 32nd U.S. Symposium on Rock Mechanics (USRMS), 10-12 July, Norman, Oklahoma; 10-12 July 1991; Norman, Oklahoma. American Rock Mechanics Association; 1991. p. 231-240. 
[30] Hubbert MK and Willis DG. Mechanics of hydraulic fracturing. Transactions of Society of Petroleum Engineers of AIME. 1957;210:153-168.

[31] Shen W, Zhang B. Testing study on mechanical parameters of coal. Chinese Journal of Rock Mechanics and Engineering. 2000;19(S1):860-862 (in Chinese).

[32] Barree RD, Fisher MK, Woodroof RA. A practical guide to hydraulic fracture diagnostic technologies. In: SPE Annual Technical Conference and Exhibition; 29 September-2 October 2002; San Antonio, Texas. Society of Petroleum Engineers; 2002. p. 1-12. DOI: 10.2118/77442-MS.

[33] Fisher MK, Heinze JR, Harris CD, Davidson BM, Wright CA, Dunn KP. Optimizing horizontal completion techniques in the Barnett shale using microseismic fracture mapping. In: SPE Annual Technical Conference and Exhibition; 26-29 September 2004; Houston, Texas. Society of Petroleum Engineers; 2004. p. 1-11. DOI: 10.2118/90051-MS.

[34] Warpinski N, Kramm RC, Heinze JR, Waltman CK. Comparison of single- and dualarray microseismic mapping techniques in the Barnett shale. In: SPE Annual Technical Conference and Exhibition; 9-12 October 2005; Dallas, Texas. Society of Petroleum Engineers; 2005. p. 1-10. DOI: 10.2118/95568-MS.

[35] Tezuka K, Kamitsuji R, Tamagawa T. Fractured reservoir characterization incorporating microseismic monitoring and pressure analysis during massive hydraulic injection. In: International Petroleum Technology Conference; 3-5 December 2008; Kuala Lumpur, Malaysia. International Petroleum Technology Conference; 2008. p. 1-7. DOI: 10.2523/ IPTC-12391-MS. 